\title{
RISK CRITCALITY AND ALLOCATION IN \\ PRIVATISED WATER SUPPLY PROJECTS IN INDONESIA
}

\begin{abstract}
:
Public-Private-Partnership (PPP) infrastructure projects typically involve a plethora of risks. Given that many risks which are traditionally borne by the government get transferred to the private sector, careful risk allocation is considered to be the key to successful PPP projects. This paper focuses on the current risk allocation practice within Indonesia's water supply projects. The paper captures, presents and discusses the perceptions of both regulators and operators in the context of project risk criticality and allocation. Both parties consider nonavailability of raw water is of paramount concern. However, survey findings highlight low-tomoderate levels of intra-group and inter-group agreement regarding the allocation of specific project risk factors. Thus, asserting that the issue of optimal risk allocation remains elusive.
\end{abstract}

Keywords: Indonesia, private sector, water supply, criticality, risk allocation

\section{INTRODUCTION}

Experts believe that the world population has increased by a factor of about three during the $20^{\text {th }}$ century, whereas water consumption has increased by a factor of about seven. Furthermore, the ratio of the world's population living in medium-to-high water-stressed countries is expected to grow from currently one-third to two-thirds by 2025 (Agarwal et al., 
2000). Despite the controversy surrounding the human's basic right to access water, and the pro-poor water governance, the growing water scarcity has transformed water from traditional public good to a commodity that has an economic value. This paradigm shift has gained international acceptance by governments and water industry alike. In 1992, the International Conference on Water and Environment held in Dublin, Ireland, released a statement (also known as the Dublin Principles), setting out four principles of addressing the issues of scarcity and misuse of fresh water. One of the four principles clearly states that water has an economic value and should be recognized as an economic good. Interested readers are referred to Rogers et al., (1996) for a detailed discussion on this particular principle.

Failure to effectively and efficiently manage water resources might lead to crisis which, if not properly addressed, can translate into social and political problems. Alexander (2002) argues that such problems may not arise due to the lack of water, but rather, because of the way water is being (mis)managed. For many years, sectoral approaches to water resource management have prevailed, leading to fragmented and un-coordinated management of precious water resources (Agarwal et al., 2000). The situation is much more severe in less-developed countries which often lack the adequate financial and managerial capacities giving rise to low coverage, inferior quality of water provided to the public, and high non-revenue water (NRW) rates. NRW herein refers to the water that has been produced, and is "lost" before it reaches the customer - put simply, it is the water not billed for authorized consumption.

Driven by fiscal constraints and widespread disenchantment with the performance of stateprovided infrastructure services, more and more governments are turning to private sector solutions for financing and providing basic infrastructure services (Dailami and Klein, 1997). The private sector is believed to be able to leverage the much-needed resources to allow for 
greater efficiency and timely investment. According to Annez (2006), no discussion of urban infrastructure finance could be complete without discussing private participation.

Since the 1980's, many developed and less-developed countries have experimented with the privatization of water systems as a means of boosting investment and increasing coverage, efficiency, and water quality (Clarke et al., 2004). About 10 years ago, a macro-economic study concluded that the private sector is more efficient in the context of the provision of water services in the Asia Pacific region (Estache and Rossi, 1999). A more recent study (Hassanein and Khalifa, 2007) reported better performance by the private sector (compared to its public counterpart) in both the US and UK water industries; in terms of staff number per 1,000 connections, return on equity, and tariffs charged. However, the private sector is mindful of the plethora of risks and uncertainties associated with water supply projects. Should these risks materialize; the project cost will almost likely be much higher than initially estimated. Water supply projects are typically characterized by substantial initial fixed cost, diverse users of service, regulatory hurdle rates, high sunk costs, risk of asset-stranding as conditions change, externalities not reflected in service charges, and long lead-times for upgrading (Clough et al., 2004). Lower-than-expected performance by the private sector in water supply projects has also been reported (Abdul-Aziz, 2001).

The situation becomes more obvious in the public-private-partnership (PPP) arrangement where an optimal risk allocation remains obscure. PPP is a contractual agreement formed between public and private sector partners which allows more private sector participation in the provision of public goods and services. Although, the PPP is not new as some countries have applied it for centuries (Namblard, 2000), it has, in practice, alternative appealing names and acronyms (Yescombe, 2007) including: private sector participation in infrastructure (PPI), 
private sector participation (PSP), P3, privately-financed projects (PFP), P-P Partnership, and the private finance initiative (PFI). Regardless of the acronym, PPP is fundamentally about risk sharing (Roumboutsos and Anagnostopoulos, 2008). In a typical PPP arrangement, if risk is inappropriately transferred to the private sector, the Government may pay a premium, or jeopardize the long-term sustainability of the arrangement (Partnerships Victoria, 2001). Two additional features of water supply projects make the above situation even more difficult. First, the potential for competition is much more limited than it is in other infrastructural sectors (e.g. electricity, telecommunication, etc.) and, secondly, privatization has proven to be more difficult and controversial than it is the case in other sectors (Clarke et al., 2004).

As with other governments, the Government of Indonesia has also been proactively encouraging private investment in the provision of public infrastructure services. However, anecdotal evidence suggests that the growth of new private investments is too slow despite the availability of ample opportunities. Two recent international events (i.e. Infrastructure Summit 2005 and 2006) hosted by the Government, have failed to attract the anticipated large number of domestic and international investors, despite claims being made by the Government that prospective investors had indeed expressed great interest in participating.

This paper presents and discusses key survey findings on how project risks are perceived and should be allocated in the context of Indonesia's water supply sector. The rest of the paper is organized as follows. To put the research into context, the next section briefly introduces the local water supply sector providing a snapshot of its past and present situations. The following sections present the research methodology and the results regarding the criticality of risks identified, perceived optimal risk allocation, and perceived risk behaviors of two major project stakeholders, namely regulators and operators representing the public and private sectors, 
respectively. Operators refer to organisations responsible for operating both water treatment plants and water supply networks. The paper ends with conclusions summarizing all key findings.

\section{INDONESIA'S WATER SUPPLY SECTOR}

The provision of water supply services is largely dominated by local operators known as PDAMs (Perusahaan Daerah Air Minum) who are expected to operate as profit-making enterprises despite being owned by the public sector. However, and according to the Indonesian Drinking Water Companies Association (Ministry of Public Works, 2005), about $90 \%$ of PDAMs are in unhealthy financial condition, with many of them are described as technically poor - reporting low levels of service. As a matter of fact, many PDAMs would have had great difficulties in sustaining their business service operations without government's financial support. Additionally, NRW rates of PDAMs-delivered water are averaging 35\% - this figure well exceeds those being reported in major cities in neighboring countries such as Kuala Lumpur (20\%) and Singapore (8\%) (Ministry of Public Works, 2004). Such high NRW rates indicate that consumers (users) are paying for system inefficiencies (Asian Development Bank, 2006).

Typical concession agreements entered into between the Government and water supply operators in Jakarta establish that tariff is set automatically every six months. The tariff structure consists of two elements: 1) water charges to be paid by the Government with NRW rates being one of the parameters, and 2) water tariff to be paid by the users. In 2007, operators submitted a proposal demanding a 30 per cent tariff increase but the Government denied their request arguing that they failed to bring NRW rates (which were hovering around 
50 per cent at the time) down to the target level of 37 per cent. However, to honour the concession agreement which stipulates semi-annual tariff increases, the Government eventually allowed the tariff to rise by no more than 10 per cent. Although insufficient to cover future investments, the operators had little choice but to accept the 10 per cent tariff increase. Clearly, if not properly resolved in the near future, the tariff problem will be a hindrance to attracting prospective investors. This signifies how imperative it is to develop a clear, fair and unambiguous tariff structure within a socially and politically tariff-sensitive environment.

Non-availability of raw water has been another common problem facing operators, especially during the dry season (April-October). It was reported that Java Island, Indonesia's most populated island, experiences around 13 billion $\mathrm{m}^{3}$ of water deficit every year. This has led the Government to alleviate millions of people and farmers impacted by the drought via a variety of supporting schemes including: free rice support, re-forestation projects, and designing less water-dependent agriculture systems (Hadad, 2003). This problem of non-availability of raw water is expected to intensify in the following years and finding a solution should be top priority for all parties involved.

Low water quality has also become a serious problem. In 2006, Perum Jasa Tirta (PJT), a state-owned enterprise responsible for supplying raw water to Jakarta area, warned that rawwater supplies cannot be guaranteed throughout the year due to water contamination. Based on a recent UN report on clean water conditions worldwide, and the data presented on 16-23 March 2003 in Kyoto (Japan), the Indonesian water quality was ranked at a very low level (i.e. ranked 110 out of 122 listed countries) (Hadad, 2003). This simply means pollution, disposal systems and sanitation are at appalling rates. 
The above facts have led the Government to initiate a restructuring program in order to help PDAMs getting out of their financial and technical troubles, so that they can effectively contribute toward achieving the ambitious targets set by the Government in the water sector. In sum, PDAMs will have to operate in a more competitive way similar to that of the private sector, and have to stop relying on government support.

At the time of writing this paper, the Government is preparing a sizeable number of water supply projects in no less than forty cities to be privately financed with a total worth of IDR 4.84 trillion (Ministry of Public Works, 2005). It worth noting that local PPP implementation in water services to-date has had mixed results; low NRW rates have been achieved on some projects, whereas much higher values as high as $50 \%$ have been reported on other projects. The latter has been the subject of recent extensive criticism by stakeholders, including: the Government, Local House of Representatives, and the Indonesian Consumer Organization.

In light of the above and as the local water industry continues to move steadily towards privatization, PDAMs will need to rely less on goverment support, improve their technical capabilities, and most importantly be capable of managing the risks not being retained by the public sector. Consequently, this study aims at investigating how both regulators and operators perceive project risks, and their allocation, in anticipation of the inevitable increasing level of privatization of Indonesia's water supply sector. Better understanding of risk criticality and allocation is pivotal to a successful PPP agenda and the Government's effort to minimize uncertainty and consumer detriment. 


\section{RESEARCH METHODOLOGY}

Given the objective of this study, a mail-based questionnaire survey was deemed appropriate for data collection as it is an efficient way to seek the experiences and perceptions of those involved in managing risks associated with the provision of local water supply projects. The survey primarily aimed at assessing individual risk's criticality and determining which party should bear what project risk. Respondents were asked to rate the criticality of each project risk on a five-point Likert rating scale ranging from 1 to 5 , representing least and most critical, respectively. As for project risk allocation, respondents had the freedom to select one party or more out of four stakeholders, namely the Government, private operators, consumers, and insurance firms to assume (or share) the risk under investigation.

To remove any ambiguities in the questionnaire, pilot-testing was carried out. Accordingly, minor amendments were made prior to mailing it out to a selected sample of regulators and operators. Sampling was not random, but was rather purposively based on preset criteria. For water operators, only city-based operators with more than 10,000 connections were selected. As for regulators, potential respondents were confined to only high-ranking officials of the Ministry of Public Works as well as the Regulating Authority for Water Resources Management - a special task unit established by the Government to regulate national water service provisions. As recommended by Ramirez and Loney (1993), only one questionnaire per operator's organization was sent out to avoid receiving multiple responses from the same organization. The questionnaire was attached to a cover letter explaining the survey, its aims, background and significance, as well as emphasizing that responses would be confidential. A self-addressed stamped envelope was also enclosed. The survey took place in July 2007. 
A total of 30 valid and useable responses were returned, representing a low but acceptable response rate of around 20 per cent. Of the respondents, a total of 43 per cent (13 responses) were regulators whereas the remaining 57 per cent $(17$ responses) were operators. The demographic background of the respondents indicated that they were senior personnel (either a director or a senior manager) and had a minimum of 10 years experience in the local water industry. In light of this, it can be concluded that the ratings of the respondents are dependable and their views are noteworthy, thus rendering validity to the survey results despite the small sample size.

\section{DATA ANALYSIS}

\section{Criticality of Identified Project Risks}

The developed questionnaire comprised a total of 39 key risks associated with PPP projects, gathered through the review of the extant literature reflecting both domestic and international practices. The identified project risks were classified into six categories (not in any specific order): Political, Macro-economic, Operational, Business, Land \& Construction, and Force Majeure as illustrated by the cause-effect diagram shown in Fig. 1. It is worth noting that the respondents did not suggest any additional risk factors, thereby confirming that all relevant project risks have been identified. All 39 risk factors were then used in the data analysis, and survey response data were entered into a database and analysed using the Statistical Package for the Social Science (SPSS version 14).

Fig.1 Cause-Effect Diagram Depicting PPP Water Supply Project Risks 
Although responses vary from one respondent to another, they typically tend to center around a single value which can be deemed to be 'representative' of risk criticality. In this part of the analysis, the key statistic used was the arithmetic mean score as it represents the central tendency measure. Table 1 exhibits the calculated mean scores and the corresponding standard error for each risk factor as viewed by the two groups of respondents. The standard error is the standard deviation of sample means, and it is a measure of how representative a sample is likely to be of the population. The standard error associated with all the means suggests some inconsistency in agreement among the respondents as the minimum obtained value was 0.182 . The table also shows the contrast in their ranking of risk criticality based on the calculated mean scores.

\begin{tabular}{|c|c|c|c|c|c|c|c|}
\hline \multirow{2}{*}{$\begin{array}{l}\text { Risk } \\
\text { Code }\end{array}$} & \multirow[t]{2}{*}{ Project Risk } & \multicolumn{3}{|c|}{ Regulators } & \multicolumn{3}{|c|}{ Operators } \\
\hline & & Mean & $\begin{array}{c}\text { Std. } \\
\text { Error }\end{array}$ & Rank & Mean & $\begin{array}{c}\text { Std. } \\
\text { Error }\end{array}$ & Rank \\
\hline $\mathrm{R} 1$ & Construction cost escalation & 4.15 & 0.191 & 3 & 4.29 & 0.254 & 5 \\
\hline $\mathrm{R} 2$ & Land cost escalation & 3.92 & 0.329 & 10 & 4.00 & 0.271 & 12 \\
\hline R3 & Construction time overrun & 3.54 & 0.433 & 19 & 4.44 & 0.182 & 4 \\
\hline $\mathrm{R} 4$ & Protacted negotiation on land price & 3.08 & 0.415 & 30 & 3.63 & 0.328 & 31 \\
\hline R5 & Tariff setting uncertainty & 4.08 & 0.445 & 7 & 4.50 & 0.258 & 1 \\
\hline R6 & General changes in legislation & 4.08 & 0.329 & 6 & 3.63 & 0.202 & 27 \\
\hline R7 & Discriminatory changes in legislation & 2.92 & 0.431 & 36 & 4.06 & 0.295 & 11 \\
\hline R8 & Specific changes in legislation & 3.92 & 0.383 & 11 & 3.81 & 0.292 & 22 \\
\hline R9 & Nationalization/Expropriation & 3.17 & 0.297 & 26 & 3.20 & 0.262 & 36 \\
\hline R10 & Non availability of foreign exchange (FX & 3.17 & 0.405 & 27 & 2.81 & 0.292 & 39 \\
\hline R11 & Transferabilty restriction of FX & 2.75 & 0.305 & 39 & 2.94 & 0.347 & 37 \\
\hline $\mathrm{R} 12$ & Exchangeability restriction of FX & 2.75 & 0.305 & 38 & 2.88 & 0.352 & 38 \\
\hline R13 & Breach of contract by government & 3.23 & 0.426 & 24 & 4.50 & 0.258 & 2 \\
\hline R14 & Premature termination by government & 3.54 & 0.418 & 18 & 4.13 & 0.291 & 10 \\
\hline R15 & Breach of contract by operator & 3.00 & 0.467 & 34 & 3.75 & 0.335 & 25 \\
\hline R16 & Premature termination by operator & 3.08 & 0.459 & 31 & 4.13 & 0.287 & 9 \\
\hline R17 & Abuse of power by government officials & 3.15 & 0.478 & 29 & 3.94 & 0.335 & 17 \\
\hline R18 & Natural disaster & 4.00 & 0.408 & 8 & 3.88 & 0.287 & 18 \\
\hline R19 & Man-made disaster & 3.38 & 0.350 & 20 & 3.63 & 0.272 & 28 \\
\hline R20 & Declared war & 2.92 & 0.415 & 35 & 3.47 & 0.322 & 34 \\
\hline R21 & Riot & 3.00 & 0.424 & 32 & 3.63 & 0.301 & 29 \\
\hline R22 & Terrorism attack & 3.00 & 0.453 & 33 & 3.88 & 0.328 & 20 \\
\hline R23 & Inflation fluctuation & 3.92 & 0.265 & 9 & 4.13 & 0.272 & 8 \\
\hline R24 & FX fluctuation & 3.77 & 0.257 & 14 & 3.67 & 0.287 & 26 \\
\hline $\mathrm{R} 25$ & Interest rate fluctuation & 3.85 & 0.249 & 13 & 3.81 & 0.292 & 23 \\
\hline R26 & Failure in financial closure & 3.69 & 0.263 & 16 & 3.50 & 0.329 & 33 \\
\hline R27 & Failure in refinancing & 3.23 & 0.361 & 23 & 4.00 & 0.289 & 13 \\
\hline R28 & Demand uncertainty & 3.15 & 0.355 & 28 & 4.00 & 0.338 & 14 \\
\hline R29 & Operation \& maintenance cost escalation & 4.15 & 0.373 & 5 & 3.94 & 0.232 & 15 \\
\hline R30 & Equipment defect-caused interruption & 4.15 & 0.355 & 4 & 3.56 & 0.258 & 32 \\
\hline
\end{tabular}




\begin{tabular}{|l|l|r|r|r|r|r|r|}
\hline R31 & Nonavailability of raw water & 4.23 & 0.411 & 1 & 4.47 & 0.259 & 3 \\
\hline R32 & Labor strike & 2.92 & 0.445 & 37 & 3.38 & 0.328 & 35 \\
\hline R33 & Technical leakage during distribution & 3.38 & 0.474 & 22 & 4.25 & 0.250 & 7 \\
\hline R34 & Electricity blackout & 3.23 & 0.496 & 25 & 3.88 & 0.301 & 19 \\
\hline R35 & Environment protest caused interruption & 3.54 & 0.402 & 17 & 3.63 & 0.315 & 30 \\
\hline R36 & Water meter manipulation & 3.92 & 0.431 & 12 & 3.94 & 0.266 & 16 \\
\hline R37 & Entry of new competitors & 4.17 & 0.241 & 2 & 3.82 & 0.214 & 21 \\
\hline R38 & Unpaid bills by consumers & 3.38 & 0.446 & 21 & 3.76 & 0.235 & 24 \\
\hline R39 & Low quality of raw water & 3.73 & 0.469 & 15 & 4.27 & 0.182 & 6 \\
\hline
\end{tabular}

Table 1 Project Risk Criticality and Mean-based Ranking ${ }^{1}$

From Table 1, the three most critical project risks for regulators were: 1) non-availability of raw water, 2) entry of new competitors, and 3) construction cost escalation. This is somewhat different for operators where the three most critical risks were: 1) tariff-setting uncertainty, 2) breach of contract by the government, and 3) non-availability of raw water. Clearly, both groups considered non-availability of raw water is of paramount concern. This is not surprising in light of the existing, and now pressing, problem of experiencing water deficit as explained above.

Although it would not be normally assumed that entry of new competitors is a highly critical risk factor for regulators, the finding here is to the contrary, especially when considering the industry characteristics which have some elements of natural monopoly. In a natural monopoly, the average cost is expected to rise as production is divided among more firms (Mankiw, 1998). So, the explanation that could be offered herein is that regulators are concerned that having more competitors (whilst tariff levels continue to be regulated) would lead to a cut-throat competitive environment which in turn might deteriorate the already inferior quality of service delivery. In other words, operators are expected to, under this scenario, sacrifice the quality of service to stay in business. Interestingly, operators did not rate this particular risk factor highly, signifying less concern about entry of new competitors.

\footnotetext{
${ }^{1}$ In case of equal means, ranking is based on mean standard error; otherwise it is based on the code order
} 
Generally, the risk ranking according to the operators concurs with the conventional wisdom of being investors concerned about the consequences of any government actions that may adversely affect project cash flows. It is, therefore, not surprising to see operators ranking tariff-setting uncertainty in the top position. At the other end of the scale, however, transferability and exchange-ability restrictions of foreign exchange (FX) were ranked bottom of the list by both groups. This is mainly because project financing in Indonesia's water industry continues to be local currency-denominated thus making these risk factors less relevant.

A closer examination of the rankings reveals that respondents, in general, rated the category comprising traditional political risks lower than other categories of risk. Given that criticality is a function of both impact and probability of occurrence; this implies that either the probability of occurrence of such risks or their impact, or both are quite low. Historically speaking, and with the exception of the nationalization of a private telecommunication

company back in the late 1970's (Wells, 1999), and the nationalization of foreign-owned companies following the proclamation of independence in 1945, traditional political risks have rarely been associated with private ventures, not to mention the business of infrastructure provision in Indonesia. Besides, the government is fully aware of the negative impact on the country's risk perception if such political risks were to materialize. This argument also explains the low rankings of non-availability (R10), transferability (R11) and exchangeability (R12) restrictions of FX which are categorized as political risk (Kerf et al., 1998).

\section{Statistical Testing for Difference in Responses}


Between the public sector purchaser and the private sector supplier, there must be sufficient convergence on opinions on the level and degree of risk to enable agreement on "price" to take place (Gallimore et al., 1997). To determine whether there were any statistical difference in the mean criticality of each risk factor between regulators and operators, a non-parametric statistical test (Mann-Whitney-Wilcoxon) was performed. This test was particularly chosen because it is distribution free; hence, it requires no assumption of normality of datasets.

The calculated Z statistics indicate that only R7 (discriminatory changes in legislation), R13 (breach of contract by government), and R28 (demand uncertainty) were statistically different in terms of mean criticality at the 95 per cent level of confidence, see Table 2. This implies that the remaining 36 risk factors were somewhat similarly selected by both groups with respect to their criticality. Therefore, it can be inferred that both groups considered the criticality of the majority of risk factors similarly at the conventional 95 per cent confidence level. A closer examination of the mean score values for the identified three risk factors (see Table 1) reveals that regulators have consistently rated them lower than how operators had. This, once again, reflects the deep concerns held by the operators regarding the uncertainty associated with risk factors which are outside their immediate control.

\begin{tabular}{|l|l|c|c|c|c|c|}
\hline $\begin{array}{c}\text { Risk } \\
\text { Code }\end{array}$ & \multicolumn{1}{|c|}{ Project Risk } & $\begin{array}{c}\text { Mann- } \\
\text { Whitney } \\
\text { (U) }\end{array}$ & $\begin{array}{c}\text { Wilcoxon } \\
\text { (W) }\end{array}$ & Z & $\begin{array}{c}\text { Asymp. Sig. } \\
\text { (2-tailed) }\end{array}$ & $\begin{array}{c}\text { Exact Sig. } \\
\text { [2*(1-tailed Sig.)] }\end{array}$ \\
\hline R7 & Discriminatory changes in legislation & 59.00 & 150.00 & 2.044 & 0.041 & 0.050 \\
\hline R13 & Breach of contract by government & 48.00 & 139.00 & 2.641 & 0.008 & 0.013 \\
\hline R28 & Demand uncertainty & 54.50 & 145.50 & 2.061 & 0.039 & 0.046 \\
\hline
\end{tabular}




\section{Intra-Group Agreement on Risk Allocation}

The term 'risk allocation' refers to the determination of which party or parties should bear the consequence(s) of events identified as project risks. How risk is shared or allocated between the parties involved is central to the PPP arrangement in terms of definition, contract negotiation, achievement of value-for-money, and overall project success (Roumboutsos and Anagnostopoulos, 2008). Best practice of PPP implementation recommends optimal rather than maximum risk transfer (United Nations Industrial Development Organization UNIDO, 1996). While the government understandably wants to transfer most of the risks to the private sector, the private sector, on the other hand, is anxious to reduce its exposure to the risks (United Nations Industrial Development Organization UNIDO, 1996). An optimal risk allocation dictates that a particular risk needs to be retained by the party, who: (a) is best able to assess, control, and manage the risk; or (b) has the best access to hedging instruments; or (c) has the greatest ability to diversify the risk; or (d) assumes the risk at lowest cost (Hadad, 2003, Shen et al., 2006, Aziz, 2007). In practice, however, the application is not as simple as it may appear, even for professionals who have been working for many years in the field, as suggested by the study findings presented below.

To determine who retains what project risk seems to be a straightforward task for certain types of risk. However, project risks in many situations need to be negotiated between the two contracting parties to determine to what extent each contracting party is held responsible for risk materialization. As noted previously, the survey invited respondents to nominate the party or parties considered most capable of assuming and retaining each and every one of the 39 risk factors under investigation. The statistical measure of dispersion, index of diversity (ID), was initially used to determine the variation in responses. Based on the proportion of responses in 
each category, Equation (1) was used to calculate the ID score for each risk factor (Weisberg, 1992).

$I D_{i}=1-\sum_{j=1}^{n}\left(w_{i j}\right)^{2}$

Where, $w_{i j}=$ proportion of cases nominating party $j$ for retaining a particular risk factor.

Due to having four parties (i.e., government, operator, consumers and insurance firms), a uniform distribution of responses among them will give rise to a maximum ID score of 0.75 reflecting a very high level of disagreement among respondents regarding which party should retain a particular risk. This was definitely the case with risk factors R18 and R19 (natural and man-made disasters) where the two groups of respondents felt that all four parties should jointly somehow bear the consequences of such risks. A moderate level of agreement, however, was indicated by ID scores between $0.35-0.45$. The computed values highlight a moderate level of agreement within each group of respondents regarding the allocation of two specific risk factors to operators namely, R26 (failure in financial closure) and R27 (failure in refinancing). It is interesting to report that a low level of agreement within each group was highly noticeable regarding the allocation of the majority of risk factors which are universally fundamental to the project success, thus a further data analysis is warranted as reported below.

The most straightforward approach to evaluating agreement is to consider the proportion of ratings upon which respondents agree. The proportion of intra-group agreement obtained specifically to each of the four parties and the overall intra-group agreement across all four parties, were calculated. Equations (2) and (3) were simply applied to determine the simple raw agreement indices for the intra-group specific and overall agreements, respectively (Uebersax, 2006). 
$p_{s}(j)=\frac{\sum_{k=1}^{K} n_{j k}\left(n_{j k}-1\right)}{\sum_{k=1}^{K} n_{j k}\left(n_{k}-1\right)}$

$p_{0}=\frac{\sum_{j=1}^{C} \sum_{k=1}^{K} n_{j k}\left(n_{j k}-1\right)}{\sum_{k=1}^{K} n_{k}\left(n_{k}-1\right)}$

Where,

$p_{\mathrm{s}}(j)=$ the proportion of agreement specific to party $j$ and is equal to the total number of agreements on party $j$ divided by the total number of opportunities for agreement on this particular party, $p_{0}=$ the proportion of overall agreement amongst a group of respondents, $K=$ number of risk factors, $C=$ number of parties nominated to retain risk factor $k$, and $n_{\mathrm{jk}}=$ the number of times party $j(j=1,2, \ldots, C)$ is allocated risk factor $k$. When there is a complete agreement on a certain party retaining a particular risk factor, $p_{s}(j)$ will take on the value of 1 .

Obtained $p_{\mathrm{s}}(j)$ values (range $\left.0.15-0.46\right)$ reflected slight to moderate agreement, within each of the two groups of respondents, specific to each of the four parties that should assume a certain risk factor. The computed proportions of overall agreement $\left(p_{0}\right)$ were 0.38 and 0.35 for regulators and operators, respectively indicating a fair agreement level.

\section{Inter-Group Agreement on Risk Allocation}

While a specific raw agreement index measures the unanimity within a group of respondents for all types of risk factors, a specific inter-group agreement index denotes the agreement level between two different groups for a specific risk factor in the context of which party should retain the risk. The proportion of inter-group agreement obtained specifically to each of the 39 risk factors and the overall inter-group agreement across all risk factors, were calculated using equations (4) and (5), respectively. 
$r_{0}=\sum_{i=1}^{C} a_{i i}$ where, $a_{i j}=\pi_{1 i} \pi_{2 j} \forall i, j$

$$
r_{s}(j)=\frac{2 a_{j j}}{\sum_{i=1}^{C} a_{i j}+\sum_{j=1}^{C} a_{i j}} \quad \forall j
$$

Eq. (4) calculates the probability of both groups opting for party $j$ to retain a particular risk factor $k . \pi_{1 j}=$ group 1 's relative frequency for nominating party $j, \pi_{2 j}=$ group 2 's relative frequency for party $j$, and $r_{0}=$ the proportion of inter-group overall agreement. When there is a complete agreement between all respondents from the two groups of respondents on a certain party retaining a particular risk factor, $r_{0}$ will take on the value of 1 . Whereas, a perfect disagreement or $r_{0}=0$, is obtained when all members of one group nominates a different party to that nominated by all members of the second group.

Eq. (5) calculates the extent of agreement between the two groups opting for party $j$ to assume risk factor $k . r_{\mathrm{s}}(j)=$ specific inter-group agreement index for party $j$ and reflects the probability of either group nominating party $j$ conditional on the other group opting for the same party. Table 3 lists the calculated measures of specific and overall agreements for all risk factors. Main findings are discussed below.

Table 3 Calculated Measures of Specific and Overall Inter-Group Agreement

\begin{tabular}{|l|l|c|c|c|c|c|}
\hline \multirow{2}{*}{$\begin{array}{l}\text { Risk } \\
\text { Code }\end{array}$} & \multicolumn{1}{|c|}{ Project Risk } & \multicolumn{3}{|c|}{ Level of specific inter-group agreement } & Overall \\
\cline { 3 - 6 } & & Government & Operator & Consumer & Insurance & \\
\hline R1 & Construction cost escalation & 0.36 & 0.42 & 0.06 & 0.00 & 0.33 \\
\hline R2 & Land cost escalation & 0.42 & 0.48 & 0.00 & 0.00 & 0.41 \\
\hline R3 & Construction time overrun & 0.21 & 0.60 & 0.06 & 0.00 & 0.41 \\
\hline R4 & Protacted negotiation on land price & 0.43 & 0.45 & 0.00 & 0.08 & 0.40 \\
\hline R5 & Tariff setting uncertainty & 0.44 & 0.31 & 0.21 & N/A & 0.35 \\
\hline R6 & General changes in legislation & 0.45 & 0.24 & 0.21 & 0.07 & 0.31 \\
\hline R7 & Discriminatory changes in legislation & 0.57 & 0.17 & 0.23 & 0.00 & 0.41 \\
\hline R8 & Specific changes in legislation & 0.56 & 0.23 & 0.20 & N/A & 0.41 \\
\hline R9 & Nationalization/Expropriation & 0.52 & 0.26 & 0.10 & 0.00 & 0.36 \\
\hline R10 & Non availability of FX & 0.34 & 0.55 & 0.00 & 0.00 & 0.44 \\
\hline
\end{tabular}




\begin{tabular}{|c|c|c|c|c|c|c|}
\hline R11 & Transferabilty restriction of FX & 0.30 & 0.54 & 0.00 & 0.08 & 0.40 \\
\hline R12 & Exchangeability restriction of FX & 0.33 & 0.40 & 0.00 & 0.09 & 0.31 \\
\hline R13 & Breach of contract by government & 0.49 & 0.33 & N/A & 0.12 & 0.38 \\
\hline R14 & Premature termination by government & 0.45 & 0.37 & 0.00 & 0.09 & 0.35 \\
\hline R15 & Breach of contract by operator & 0.11 & 0.68 & 0.08 & 0.13 & 0.50 \\
\hline R16 & Premature termination by operator & 0.24 & 0.50 & 0.10 & 0.12 & 0.35 \\
\hline R17 & Abuse of power by government officials & 0.70 & 0.16 & 0.13 & N/A & 0.54 \\
\hline R18 & Natural disaster & 0.38 & 0.18 & 0.07 & 0.32 & 0.29 \\
\hline R19 & Man-made disaster & 0.28 & 0.20 & 0.09 & 0.35 & 0.27 \\
\hline R20 & Declared war & 0.58 & 0.00 & 0.00 & 0.21 & 0.39 \\
\hline R21 & Riot & 0.47 & 0.10 & 0.00 & 0.20 & 0.29 \\
\hline R22 & Terrorism attack & 0.50 & 0.00 & 0.00 & 0.24 & 0.33 \\
\hline R23 & Inflation fluctuation & 0.39 & 0.43 & 0.07 & 0.07 & 0.36 \\
\hline R24 & FX fluctuation & 0.35 & 0.45 & 0.00 & 0.07 & 0.35 \\
\hline $\bar{R} 25$ & Interest rate fluctuation & 0.42 & 0.42 & 0.00 & 0.00 & 0.37 \\
\hline R26 & Failure in financial closure & 0.12 & 0.75 & N/A & 0.09 & 0.59 \\
\hline R27 & Failure in refinancing & 0.11 & 0.75 & 0.09 & 0.00 & 0.58 \\
\hline R28 & Demand uncertainty & 0.31 & 0.42 & 0.18 & 0.00 & 0.32 \\
\hline R29 & Operation \& maintenance cost escalation & 0.29 & 0.33 & 0.27 & N/A & 0.30 \\
\hline R30 & Equipment defect-caused interruption & 0.14 & 0.34 & 0.16 & 0.16 & 0.23 \\
\hline R31 & Nonavailability of raw water & 0.66 & 0.16 & 0.18 & N/A & 0.50 \\
\hline R32 & Labor strike & 0.35 & 0.32 & 0.16 & 0.00 & 0.29 \\
\hline R33 & Technical leakage during distribution & 0.30 & 0.47 & 0.17 & 0.00 & 0.35 \\
\hline R34 & Electricity blackout & 0.32 & 0.35 & 0.25 & 0.00 & 0.30 \\
\hline R35 & Environment protest caused interruption & 0.50 & 0.26 & 0.19 & N/A & 0.36 \\
\hline R36 & Water meter manipulation & 0.10 & 0.22 & 0.52 & N/A & 0.35 \\
\hline R37 & Entry of new competitors & 0.33 & 0.34 & 0.09 & 0.06 & 0.29 \\
\hline R38 & Unpaid bills by consumers & 0.15 & 0.14 & 0.39 & N/A & 0.25 \\
\hline R39 & Low quality of raw water & 0.40 & 0.30 & 0.28 & N/A & 0.33 \\
\hline
\end{tabular}

N/A refers to "Not applicable" due to the lack of responses given to a certain party by either or both groups of respondents

Table 3 Calculated Measures of Specific and Overall Inter-Group Agreement

Since evaluating agreement is of interest, a priori level of moderate agreement for discussion was set at the lower end of 0.50 . The calculated measures, listed in Table 3, indicate that there is a moderate level of agreement on the government retaining eight risk factors: R7, R8, R9, R17, R20, R22 and R31, and on the operators retaining seven risk factors: R3, R10, R11, R15, R16, R26 and R27. R36 (water meter manipulation) was the sole risk factor that appears to be allocated to the Consumers. Only five risk factors have given rise to an overall measure that is equal to, or greater than, 0.50 . These are R17 (abuse of power by government officials) and R31 (non-availability of raw water) to be allocated to the Government, whereas R15 (breach of contract by operator), R26 (failure in financial closure) and R27 (failure in refinancing) to be allocated to operators. 


\section{DISCUSSION}

The foregoing, once again, highlights that even though both groups of respondents appear to concur on a handful of project risks, there exists the unresolved problem of allocating the remaining ones especially those identified by both groups as highly critical. The latter can be considered as 'grey' areas that require careful negotiations between the two parties before their allocation can be decided. The following discussion sheds some light on two highlyranked critical risk factors (from the operator's perspective) on which both parties appear to fail reach a reasonable level of agreement on risk allocation.

\section{Tariff-setting uncertainty}

Tariff-setting is a volatile and sensitive issue. Despite tariff risk falling under the control of the government, the respondents see it not necessarily resting with the government. There exists a low level of agreement between the two groups of respondents, with the regulators believing that this risk needs to be transferred to the private operators, while their counterparts argue that it must be a government's responsibility. However, it would seem that if the government insists on transferring this risk, the operators will almost likely charge a much higher risk premium than necessary; without such increases, they will be reluctant to participate in the project. This problem warrants a prompt action and quick resolution by the government. Delay will inevitably result in increased uncertainty and the continued negative impact on investors' confidence.

Indonesia's water supply sector believes a vicious circle exists between tariff setting and having a minimum required service level. Both subjects are typically stipulated, but individually handled in a contract. Thus, a common problem encountered is that the water operator claims to be unable to meet the required level of service because the tariff has not 
been adjusted. And on the other hand, the government rejects any proposals to increase tariffs if the operator is unable to deliver at the level required. One possible solution to address this problem is directly linking tariff adjustment formulas to performance indicators, such as NRW rates and coverage rates. A tariff formula being linked to performance is not uncommon for PPP projects. In some countries, the United Kingdom for instance, the price-cap formula takes into account both future inflation and the future efficiency gains expected from the utility (Kerf et al., 1998). In many respects, this concept could be adopted for the Indonesian water sector in the context of achieving an agreed-upon performance level.

\section{Breach of contract by government}

As indicated previously, water supply service provision in Indonesia remains a politically sensitive issue because it deals with the public right to access water. Thus, operators appear to be of the view that the government might be tempted to renege on its contractual agreements for any (popular) political reasons. If this were to eventuate, it would certainly have considerable financial impacts on their profitability. In this context, the key challenge for the government right now is to identify how to change this perception thus increasing the private sector's confidence and in turn, allaying investors' concerns.

A third risk factor non-availability of raw water was identified by both groups of respondents as of paramount concern. Study findings suggest a moderate level of agreement exists on retaining this risk factor by the government, however, the reader is reminded that the operator, in practice, is often required to provide the customers with a guarantee that quality water will be delivered on time. In such a case, the risk is resting with the operator if they were unable to meet the service target. It is somewhat problematic if the operator is compelled to seek alternative raw water sources, in the event of their non-availability, from PJT, the state-owned 
raw water supplier who itself is unable to guarantee raw water supplies. Incidentally, PJT is the only institution entitled to manage raw water sources. To overcome this problem, the contract entered into by the government and the private operator needs to clearly define (measurable) events, including those attributed to a third party (e.g. PJT), which can relieve the contracting parties from meeting their contractual obligations, and trigger the provision of compensations and penalties, if applicable. Should the Government mandate PJT to meet the so-called public service obligation, a financial compensation must be provided to allow PJT to earn a fair profit.

\section{CONCLUDING REMARKS}

A typical PPP arrangement is exposed to a plethora of risks. Thus, it is of paramount importance to carefully identify and allocate all project-associated risks. This paper addressed risk criticality and allocation in the context of PPP water supply development projects in Indonesia. Out of the identified 39 risk factors, the top three ranked factors according to the industry's survey were: non-availability of raw water, entry of new competitor, and construction cost escalation from the regulator's perspective; and, tariff-setting uncertainty, breach of contract by government, and non-availability of raw water from the operator's perspective.

It has been asserted that private sponsors will normally agree to bear risks that are familiar to them, such as most of the development, construction, commissioning and operating risks, but will hesitate to agree to bear uninsurable risks that are unquantifiable and outside their control, such as some political risks and country commercial risks, indeterminate demand risks, and uninsurable force majeure risks (Asian Development Bank, 2006). To some extent, the survey 
findings seem to confirm this normal practice, especially for project risk allocation on which both regulators and operators moderately agree. It has also been presumed that the regulators would be tempted to transfer as many project risks as possible, while the operators were expected to accept as few project risks as possible.

The survey findings, however, do not provide strong evidence in support of this assumption. Both intra- and inter-group agreements highlight a clear disagreement between the two contracting parties when dealing with the issue of who assumes what risk? especially for critical risk factors. For any PPP arrangement to succeed, it is important that project risks be optimally allocated. Even so, it is certainly not less important to unambiguously define the party required to assume a particular risk, irrespective of whether the allocation is optimal or not. A potential dispute often stems from the incomprehensible contractual risk allocation. Sometimes, such a dispute invites mixed comments from a non-contracting party claiming to represent the public interest.

It is pleasing to report that only recently, as part of a national initiative to attract private funding to the critical infrastructure sector, the Indonesian government has embarked on a policy framework of risk allocation and sovereign support, promulgated via a Ministerial Decree. This decree covers political, performance and demand project risks. Although the framework has not been tested in practice, at least at the time of writing this paper, the government appears to be willing to share some specific project risks (e.g., those associated with land-procurement and tariff-setting) with the private sector. In principle, the government would provide some guarantees and compensations (if necessary) to private investors, if they were to be disadvantaged due to the eventuation of an identified project risk, and their inability to control the consequences of the risk if it materializes. To demonstrate, a 'capped' 
land cost arrangement is guaranteed by the government. If the actual cost exceeds the guaranteed cost (capped at $110 \%$ of the expected cost), then the government will pay the balance. Currently, the Ministry of Finance is believed to be in the process of estimating the funds required to implement such a scheme as it may expose the government to substantial contingent liabilities.

The government is also considering imposing a new tax regulation on the use of ground water in an attempt to minimize water demand risk for operators in the greater Jakarta area. To date, the prevailing tax rates are not conducive for users to use piped water due to its relatively high cost. This leads to excessive groundwater-pumping that is allegedly responsible for sinking groundwater level in the city. These tax rates may encourage consumers (i.e. households and industries) to rely more on piped water usage.

It is noteworthy that a project must meet pre-determined stringent criteria to be considered eligible for the above scheme. These criteria include: transparency, fiscal prudence, acceptable cost-benefit ratio, to name but a few. Nevertheless, it is a step in the right direction to boost the investor's confidence. Finally, it is imperative to properly define project risk allocation in the contract, and for both parties to give a strong commitment to fulfilling the contractual agreement.

\section{STUDY LIMITATIONS}

The results presented herein should be interpreted in light of two limitations. First and foremost, the small sample size used to gather information. This has obviously diminished statistical power. Second, the study was focused on one infrastructure sector in one country. Thus, the results may not generalize to other infrastructure sectors or countries. Further 
research is needed to expand our understanding on the underlying assumptions used by government to retain a particular risk, or allocate it to the private sector. Understanding the mechanism guiding the formation of risk allocation strategies by the Indonesian government to attract (or otherwise) private investment to this critical infrastructure sector would go a long way in shaping the private sector’s commitment.

\section{ACKNOWLEDGMENT}

The authors wish to acknowledge the Australia-Indonesia Governance Research Partnership (AIGRP), an Australia Government Initiative, for the full financial support of this research. Any views expressed in this paper are those of the authors and do not necessarily represent the policy of the AIGRP and the institutions the authors are affiliated with. The authors would also like to thank the anonymous reviewers of JPMA for their helpful comments. 


\section{REFERENCES}

Abdul-Aziz, A.R., 2001. Unraveling of BOT Scheme: Malaysia’s Indah Water Konsortium. Journal of Construction Engineering and Management, 127 (6), 457-460.

Agarwal, A., Angeles, M. S. D., Bhatia, R., Chéret, I., Davila-Poblete, S., Falkenmark, M., Villarreal, F. G., Jønch-Clausen, T., Kadi, M. A., Kindler, J., Rees, J., Roberts, P., Rogers, P., Solanes, M., Wright, A., 2000. Integrated Water Resources Management. Technical Advisory Committee Background Papers, 4. Stockholm, Sweden, Global Water Partnership.

Alexander, W., 2002. No water, no future: a water focus for Johannesburg. www.nowaternofuture.org/pdf/NoWaterNoFuturre\%20Final\%20Version.pdf [accessed 09.01.2008]

Annez, P. C., 2006. Urban infrastructure finance from private operators: what have we learned from recent experience? Policy research working paper WPS4045. Washington DC, World Bank.

Asian Development Bank, 2006. Non-revenue Water: A Governance Challenge. http://www.adb.org/water/topics/non-revenue/default.asp [accessed 22.6.2007]

Aziz, A. M. A., 2007. Successful Delivery of Public-Private Partnerships for Infrastructure Development. Journal of Construction Engineering and Management 133 (12), 918931.

Clarke, G. R. G., Kosec, K., Wallsten, S., 2004. Has private participation in water and sewerage improved coverage? - Empirical evidence from Latin America. Policy Research Working Paper, WPS3445. Washington D.C., World Bank.

Clough, P., Duncan, I., Steel, D., Smith, J., Yeabsley, J., 2004. Sustainable infrastructure: A policy framework http://www.med.govt.nz/upload/18061/nzier.pdf [accessed 10.10.2007] 
Dailami, M., Klein, M. U., 1997. Government Support to Private Infrastructure Projects in Emerging Markets. Dealing with public risk in private infrastructure, 17322. World Bank, 21-42.

Estache, A., Rossi, M. A., 1999. Comparing the performance of public and private water companies in the Asia and Pacific Region: what a stochastic costs frontier shows Policy research working papers, 2152. Washington, D.C., World Bank.

Gallimore, P., Williams, W., Woodward, D., 1997. Perceptions of risk in the private finance initiative. Journal of Property Finance, 8 (2), 164-175.

Hadad, N., 2003. Water privatization in Indonesia. http://www.infid.org/newinfid/olddocu/water.pdf [accessed 18.1. 2008]

Hassanein, A. A. G., Khalifa, R. A., 2007. Financial and operational performance indicators applied to public and private water and wastewater utilities. Journal of Engineering, Construction and Architectural Management, 14 (5), 479-492.

Kerf, M., Gray, R. D., Irwin, T., Levesque, C., Taylor, R. R., Klein, M., 1998. Concessions for infrastructure: a guide to their design and award. 399. Washington D.C., World Bank.

Mankiw, N. G., 1998. Principles of Economics, Orlando, the Dryden Press.

Ministry of Public Works, 2004. Water supply investment opportunities in Indonesia. Jakarta, Ministry of Public Works.

Ministry of Public Works, 2005. Penyelenggaraan sistem penyediaan air minum. Jakarta (in Bahasa Indonesia), Ministry of Public Works.

Namblard, C., 2000. In favor of a pragmatic approach towards public-private-partnership. In PERROT, J.-Y., CHATELUS, G. (Eds.) Financing of Major Infrastructure and Public Service Projects: Lessons from French Experience throughout the World. Paris, Pressess de l'ecole nationale des Ponts et Chaussées. 
Partnerships Victoria, 2001. Public Sector Comparator: Supplementary Technical Note [accessed 22.6.2007]

Ramirez, C., Loney, T., 1993. Baldrige Award winners identify the essential activities of a successful quality process. Quality Digest, January, 38-40.

Rogers, P., Bhatia, R., Huber, A., 1996. Water as a social and economic good: how to put the principle into practice? Technical Advisory Committee Background Papers, Stockholm, Sweden, Global Water Partnership.

Roumboutsos, A., Anagnostopoulos, K., 2008. Public-private partnership projects in Greece: risk ranking and preferred risk allocation. Construction Management and Economics, 26 (7), 751-763.

Shen, L.-Y., Platten, A., Deng, X. P., 2006. Role of public private partnerships to manage risks in public sector projects in Hong Kong. International Journal of Project Management, 24 (7), 587-594.

Uebersax, J. S., 2006. Raw Agreement Indices. http://www.john-uebersax.com/stat/raw.htm [accessed 10.5.2008]

United Nations Industrial Development Organization (Unido), 1996. Guidelines for infrastructure development through build-operate-transfer (BOT) projects. Vienna.

Weisberg, H. F., 1992. Central tendency and variability, London, Sage Publications.

Wells, L. T., 1999. Private foreign investment in infrastructure: managing non-commercial risk. Rome, 8-10 September, Preliminary Draft, www.worldbank.org/html/fpd/risk/papers.htm [accessed 12.8.2008]

Yescombe, E. R., 2007. Public-Private-Partnerships: Principles of Policy and Finance, Oxford, Butterworth-Heinemann. 